\title{
PARECERISTAS AD HOC 2019
}

O Comitê Editorial dos Cadernos CEDES agradece a colaboração dos pareceristas ad hoc elencados a seguir, que emitiram pareceres e promoveram, com sua experiência e seu profissionalismo, a avaliação dos números temáticos publicados por este periódico no ano de 2019.

- Cláudia Valentina Assumpção Galian (Universidade de São Paulo - USP)

- $\quad$ Ilza Zenker Leme Joly (Universidade Federal de São Carlos — UFSCar)

- João Augusto Gentilini (Universidade Estadual Paulista "Júlio de Mesquita Filho" - Unesp)

- Josélia Gomes Neves (Universidade Federal de Rondônia — Unir)

- Laura Chalub (Universidade Estadual Paulista 'Julio de Mesquita Filho)

- $\quad$ Leda de Albuquerque Maffioletti (Universidade Federal do Rio Grande do Sul — UFRGS)

- $\quad$ Regis Eduardo Coelho Arguelles da Costa (Universidade Federal do Estado do Rio de Janeiro - Unirio)

- $\quad$ Sabrina Moehlecke (Universidade Federal do Rio de Janeiro UFRJ)

- Valeria Rebolledo Angulo (Centro de Cooperación Regional para la Educación de Adultos en América Latina y el Caribe Crefal, México)

DOI: 10.1590/CC0101-32622019v39n109LIST

(C) 2019 Centro de Estudos Educação e Sociedade - CEDES Este é um artigo de acesso aberto distribuído nos termos de licença Creative Commons.

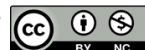

